\title{
Food Habits and Diabetes Mellitus in Female Patients in Hail City
}

\author{
Shahida Banu Shamsuddeen*, Marivic R. Jamison*, \\ Manar Mlih Sabih Al Shammary* \\ *( Department of Clinical Nutrition, College of Applied Medical Science, University of Hail, Saudi Arabia) \\ **(Student, Department of Clinical Nutrition, College of Applied Medical Science, University of Hail, Saudi \\ Arabia)
}

\section{Introduction}

Diabetes mellitus (DM), or simply diabetes, is a group of metabolic diseases in which a person has high blood sugar, either because the pancreas does not produce enough insulin, or because cells do not respond to the insulin that is produced [1]. This high blood sugar produces the classical symptoms of polyuria (frequent urination), polydipsia (increased thirst) and polyphagia (increased hunger).

The World Health Organization (WHO) defines diabetes as a metabolic disorder of multiple etiologies characterized by chronic hyperglycemia with disturbances of carbohydrate, fat, and protein metabolism that results from defects in insulin secretion, insulin action, or both. Diabetes mellitus is by far the most common metabolic disorder, its prevalence varying widely worldwide and ranging from as low as $<1 \%$ to $>50 \%$ [2-7]. Diabetes is associated with reduced life expectancy; the significant morbidity associated with diabetes arises from micro vascular complications, increased risk of macro vascular complications (ischemic heart disease, stroke, and peripheral vascular disease), and diminished quality of life [8]. There are three main types of DM.

- Type 1 DM results from the body's failure to produce insulin. This form was previously referred to as "insulin-dependent diabetes mellitus" (IDDM) or "juvenile diabetes".

- Type 2 DM results from insulin resistance, a condition in which cells fail to use insulin properly. This form was previously referred to as non insulin-dependent diabetes mellitus (NIDDM) or "adult-onset diabetes".

- The third main form, gestational diabetes occurs when pregnant women without a previous diagnosis of diabetes develop a high blood glucose level. It may precede development of type $2 \mathrm{DM}$.

Diabetes mellitus (DM) is an increasing public health problem worldwide [9]. The global epidemic of people with type II diabetes is largely due to population growth, aging, urbanization, and the scourge of obesity and physical inactivity. The total number of people worldwide with type II diabetes was expected to increase from 171 million in 2000 to 366 million in 2030 [10]. According to the international Diabetes Federation (IDF) the prevalence worldwide already reached 366 by 2011 and could well reach 530 million people in 2030 [10]. Diabetes mellitus the most common chronic endocrine disorder affecting an estimated 5\% to $10 \%$ of the adult population in industrialized Western countries, Asia, Africa, Central America and South America, and it has a large impact on society $[10,11,12]$. There is an increased concern about the rising tide of type II diabetes and its associated complications in the Arabic-speaking countries (East Mediterranean, Arabic peninsula, and Northern Africa) as these regions have some of the highest rates of diabetes in the world [13]. The prevalence in males was $26.2 \%$ and females was $21.5 \%$, and the overall prevalence of Diabetes in adults in KSA is $23.7 \%$ in 2004 [14]. Saudi Arabia has one of the highest percentages of Diabetes in the world, with an estimated number of $2,065,300$ people diagnosed with the disease by 2010 , which is $16.8 \%$ of the population (although some studies have shown this percentage to be higher) [15]. Fewer epidemiological studies were conducted among the rapidly growing population in the Hail region of Saudi Arabia.

Therefore, we designed this study with the following objectives:

\section{Objectives}

1. To determine the demographic and social profile of diabetes mellitus in among the females in Hail city of Saudi Arabia.

2. To study the association of diabetes mellitus in relation to nutritional habits of the people of Hail.

\section{Methodology}

A cross sectional survey was planned to determine the prevalence of diabetes mellitus among the female inhabitants of Hail city of Saudi Arabia. 


\subsection{Design and Sample}

The study was designed as a cross-sectional survey conducted in Hail city during the winter $2012-13$ semester. The sample size was 80 females were randomly selected between the age group of $15 \mathrm{yrs}$ to $80 \mathrm{yrs}$ for the study. Patients visiting King Khalid Hospital of Hail City during the months of November to December, 2012 were included in this study. All questions were administered to the subjects to provide the information on their medical history of diabetes and dietary habits. Data were collected through a face-to-face interview using a structured questionnaire. The study included only female Saudi nationality with diabetes mellitus. The sample chosen was from all socioeconomic level.

\subsection{Data Collection}

Self-reported questionnaire and anthropometric measurements were used for data collection. Prior to filling out the questionnaire, the subjects were informed about the study and were given instructions on how to fill out the questionnaire completely and truthfully. Data collection was done on a standardized survey questionnaire with information related to demographic and socioeconomic details, food frequency, snacking and meal skipping pattern, frequency of eating outside, watching television, weight gain and physical activity.

Anthropometric measurements weight and height were collected using the standard procedures from the sample. Body Mass Index (BMI) was calculated according to the formula (weight $(\mathrm{kg}) / \mathrm{height}^{2}(\mathrm{mt})$ ) [16]. According to World Health Organization (WHO), 2004, [17] weight status was classified into four categories: underweight (BMI $\leq 18.5$ ), normal weight (BMI between $18.5-24.9$ ), overweight (BMI between 25-29.9), and obese $(\mathrm{BMI} \geq 30)$.

\subsection{Validation of the Questionnaire:}

For content validity (back to back translation), the questionnaire was initially translated into Arabic and then converted back to English and pre-tested for question accuracy and clarity.

\subsection{Data Analysis}

The data set was cleaned and edited for inconsistencies. Missing data were not statistically computed. Statistical analyses were performed using the Statistical Package for Social Sciences (version 16.0, SPSS, Inc) software. Descriptive statistics such as means and standard deviations were calculated for the continuous variables and frequencies for qualitative data. Associations were established using chi-square analysis. All reported $P$ values were made on the basis of 2 -sided tests and compared to a significance level of $5 \%$; differences were considered statistically significant at $\mathrm{P}<0.05$ or $\mathrm{P}<0.01$.

\section{Results}

A total of 77 female patient suffering from Diabetes mellitus were included in the study. Table No 1 presents the demographic and anthropometric profile of the study subjects $(n=80)$. The total mean age \pm SD was $40.99 \pm 20.22$ years (range 15-89). The mean BMI \pm SD was $27.85 \pm 6.02$.

Figure 1 presents the distribution of BMI groups in the study population which suggests that $2.6 \%$ were underweight, $31.17 \%$ were with normal weight while $33.77 \%$ had overweight and $32.47 \%$ were obese. Since the subjects are all diabetic, majority seems to be (nearly $66 \%$ ) either overweight or obese proving the link between them.

Table No 2 represents the demographic and medical history of the study population. Nearly $45 \%$ of the population with age 46 years and above. About $68 \%$ of the population falls in the income group of SR5000 to SR10000. There is no genetic history of the disease but frequent weight gain was seen in nearly $56 \%$ of the population. $78 \%$ of the samples did not perform any physical activity which might also be a cause of their disease.

Table No 3 represents the sample's lifestyle of meal pattern in response to the type of meal they skip, frequency of snacking and eating outside and snacking while watching television. It was estimated that nearly $66 \%$ of the sample skip their dinner. Almost half of the population eat snacks while watching television and about $60 \%$ of the population have meals outside their home like in hotels, restaurants, fast foods, cafeterias etc.

Figure 2 prevalence of other health problems. Nearly 35\% of the population suffer from high Blood Pressure and $18.2 \%$ of the sample have high level of cholesterol.

Figure 3 represents the influencing factors for frequent weight gain in the study population. It is very clear that the samples who eat outside home shows about $62.8 \%$ frequent weight gain and $40.6 \%$ shows absence of frequent weight gain those who do not eat outside home. Whereas the samples who does regular physical activity shows $87.5 \%$ absence of frequent weight gain in compare with the samples who do perform any physical activity $30.2 \%$ shows frequent weight gain. Similarly, with factors like eating while watching TV also shows $41.9 \%$ a history of weight gain and $53.1 \%$ shows absence of a history of weight gain. 


\section{Tables And Figures}

Table: 1 Demographic and Anthropometric Profile of the Study Population

\begin{tabular}{lllll}
\hline Variables & Minimum & Maximum & Mean & Std. Deviation \\
\hline Age $($ years $)$ & 15 & 89 & 40.99 & 20.22 \\
Height $(\mathrm{cm})$ & 135 & 180 & 157.30 & 8.21 \\
Weight $(\mathrm{kg})$ & 43 & 111 & 68.79 & 15.17 \\
BMI $\left(\mathrm{kg} / \mathrm{m}^{2}\right)$ & 18.1 & 42.3 & 27.85 & 6.024 \\
\hline
\end{tabular}

Figure: 1 Prevalence of BMI groups in the study diabetic population

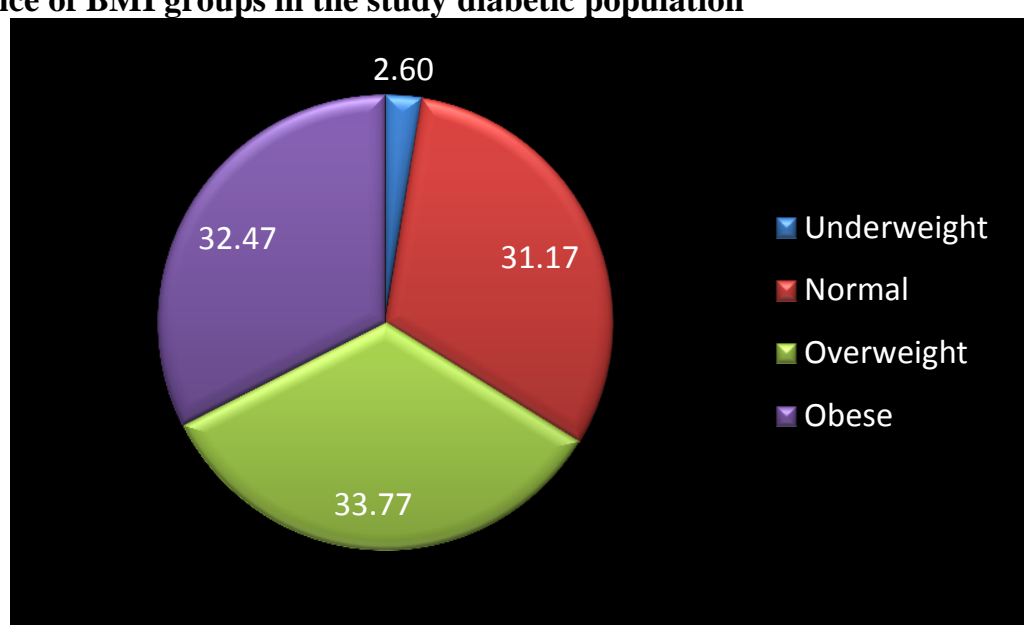

Table : 2 Characteristics of the Study Population by Demographic and Medical History

\begin{tabular}{|c|c|c|c|}
\hline \multicolumn{2}{|l|}{ Variables } & Frequency & Percentage \\
\hline \multirow[t]{2}{*}{ Age } & 45 or less yrs & 42 & 54.5 \\
\hline & 46 or more yrs & 35 & 45.5 \\
\hline \multirow[t]{3}{*}{ Income } & $<5000 \mathrm{SR}$ & 20 & 26.0 \\
\hline & $5000-10000 \mathrm{SR}$ & 52 & 67.5 \\
\hline & $>10000$ SR & 5 & 6.5 \\
\hline \multirow[t]{2}{*}{ Genetic history } & Yes & 23 & 29.9 \\
\hline & No & 54 & 70.1 \\
\hline \multirow{3}{*}{$\begin{array}{l}\text { History of frequent } \\
\text { Weight Gain }\end{array}$} & Yes & 43 & 55.8 \\
\hline & No & 32 & 41.6 \\
\hline & 3 & 2 & 2.6 \\
\hline \multirow[t]{2}{*}{ Physical activity } & Yes & 60 & 77.9 \\
\hline & No & 17 & 22.1 \\
\hline
\end{tabular}

Table: 3 Meal Patterns of the Study Population

\begin{tabular}{|l|l|l|l|}
\hline Variables & \multicolumn{2}{l|}{ Frequency } & Percentage \\
\hline \multirow{3}{*}{ Type of meal skip } & Breakfast & 14 & 18.2 \\
\cline { 2 - 4 } & Lunch & 12 & 15.6 \\
\cline { 2 - 4 } & Dinner & 51 & 66.2 \\
\hline \multirow{5}{*}{ Frequency of skipping meals } & Daily & 11 & 14.3 \\
\cline { 2 - 4 } & Weekly & 14 & 18.2 \\
\cline { 2 - 4 } & monthly & 8 & 10.4 \\
\cline { 2 - 4 } & Rarely & 44 & 57.1 \\
\hline \multirow{5}{*}{ Freq of snacking } & Once & 9 & 11.7 \\
\cline { 2 - 4 } & Twice & 16 & 20.8 \\
\cline { 2 - 4 } & Thrice & 29 & 37.7 \\
\cline { 2 - 4 } & Many times & 23 & 29.9 \\
\hline \multirow{5}{*}{ Eating snacks while watching TV } & Yes & 36 & 46.8 \\
\cline { 2 - 4 } & No & 41 & 53.2 \\
\hline Freq eating outside & Yes & 46 & 59.7 \\
\cline { 2 - 4 } & No & 31 & 40.3 \\
\hline
\end{tabular}




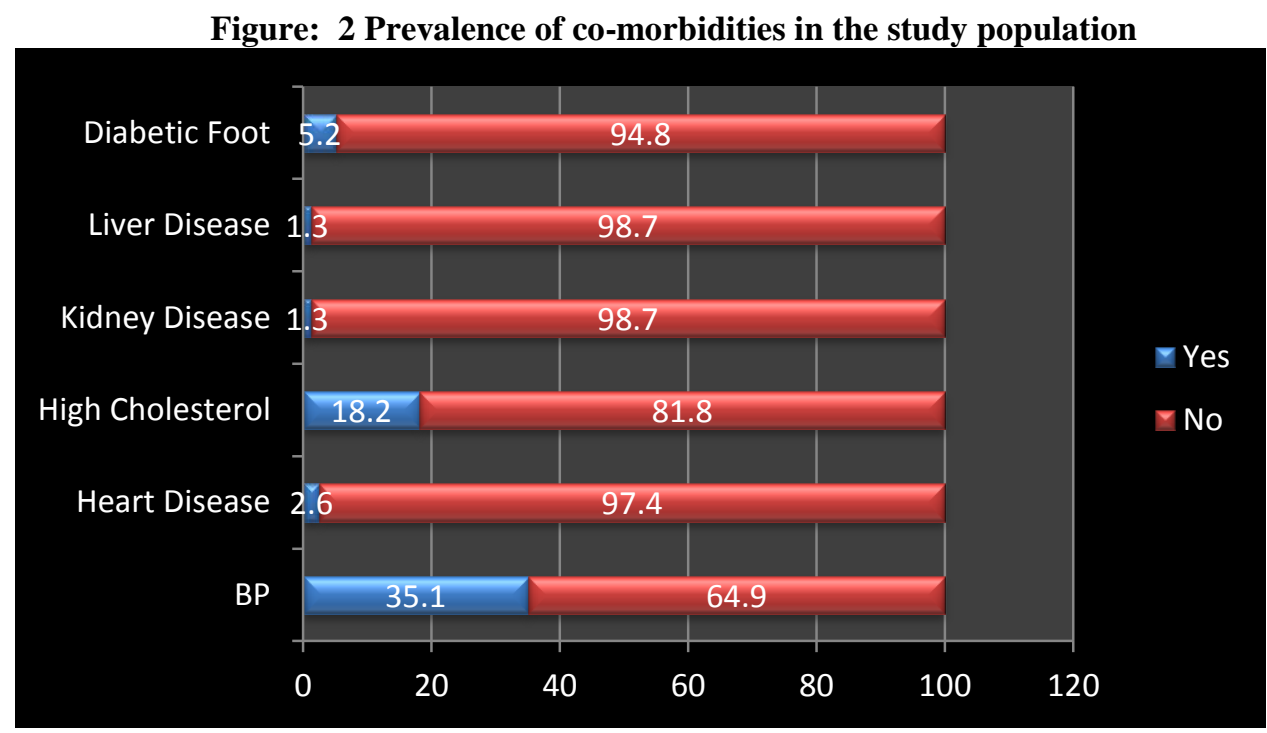

Figure. 3 History of frequent weight gain and influencing factors in the study population

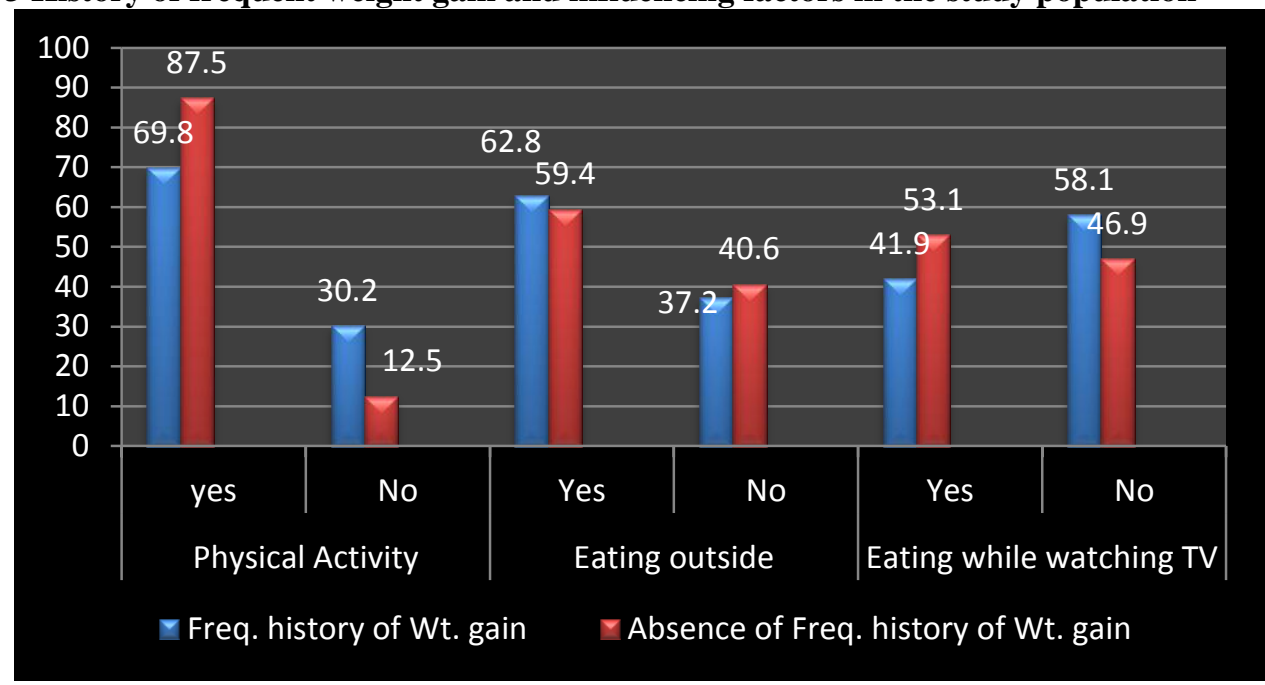

\section{Discussion}

The results from the study indicate that the study population(only females) who were diabetic was also suffering from co-morbidities and have risky dietary profile. This goes in consistency with the study done by Hassan H Fatani [18] which highlights the prevalence of diabetes among women in Saudi Arabia. The results showed an overall prevalence of diabetes was $4.3 \%$. Prevalence also differed with sex. The overall prevalence in women $(5.9 \%)$ was twice that for men (2.9\%;). Obesity occurred in $41.2 \%$ of our diabetic subjects compared to $29.3 \%$ in nondiabetic subjects. This agrees with our study on the risk factors like high prevalence of obesity, hypertension and high cholesterol along with diabetics observed in the study subjects indicate the future health complications possible for this population.

According to Sara Wild et al.,[19] worldwide prevalence of diabetes for all age-groups was estimated to be $2.8 \%$ in 2000 and $4.4 \%$ in 2030 . The total number of people with diabetes is projected to rise from 171 million in 2000 to 366 million in 2030. The prevalence of diabetes is higher in men than women, but in fact there are more women with diabetes than men. The urban population in developing countries is projected to double between 2000 and 2030. It goes in consistency with study of J.E Shaw et al., [20] which states that the world prevalence of diabetes among adults (aged 20-79 years) will be 6.4\%, affecting 285 million adults, in 2010, and will increase to $7.7 \%$, and 439 million adults by 2030. Between 2010 and 2030, there will be a $69 \%$ increase in numbers of adults with diabetes in developing countries and a $20 \%$ increase in developed countries.

The prevalence of diabetes in Saudi Arabia according to Khalid A. Alqurashi et al [21] was 34.1\% in males and $27.6 \%$ in females. Females $<50$ years old had a higher prevalence than males in the corresponding age range $34.1 \%$ and $25.1 \%$, respectively. 
According to El-Hazmi MAF, Warsy overweight and obesity are common in both males and females, particularly females [22]. From the demographic data of the survey which states that most of the population with moderate income are obese and overweight with less physical activity. A study on Lack of exercise says that the climatic conditions and the life pattern in Saudi Arabia affect the extent of physical activity carried out daily, particularly by older people. As our population are from an high altitude area it is obvious that the habit of performing physical exercise is very rare[23].

The study also predicts the lifestyle of the population. The consumption of snacks, eating outside has become very common among the sample which attribute to diabetes mellitus. The choice of food and their changed dietary habits can be a contributing factor to diabetes mellitus. Dietary habits. The Saudi diet includes a high intake of carbohydrates in the form of bread, dates, sugar, potatoes, etc. and is believed to be one of the major factors involved in obesity [23].

Genetic factors. The role of genetic predisposing factors is well established for diabetes mellitus. The finding that diabetes mellitus accumulates in Saudi families confirms that genetics has a significant role to play in the etiology of diabetes [23]. On contrary, in our study almost two third of the population predicts no genetic history of diabetes mellitus in their family.

In addition, there may be other factors which other health problems like hypertension, heart diseases, high cholesterol, kidney and liver diseases may further contribute to the development of diabetes mellitus in the Saudi population.

\section{Conclusion}

To conclude, this study provides information on the health status of the females suffering from diabetes mellitus. The study also highlights on the epidemiological information of diabetes mellitus as a health problem among females. The study also emphasizes on level of knowledge of the population about diabetes mellitus. Thus it is suggested that serious steps has to be taken on the intervention programs among the people. Soon a national level prevention program must be implemented with a broad knowledge on the diabetes mellitus relating to risk factors, management and preventive measures should be promoted in the public specially targeting high- risk groups.

\section{References}

[1]. Shoback, edited by David G. Gardner, Dolores (2011). Greenspan's basic \& clinical endocrinology (9th ed.). New York: McGraw-Hill Medical. pp. Chapter 17.

[2]. King H, Rewes M. Global estimates for prevalence of diabetes mellitus and impaired glucose tolerance in adults. WHO Ad Hoc Diabetes Reporting Group. Diabetes care, 1993, 16:157-77.

[3]. Mann JI, Pyorala K, Teuscher A. Diabetes in epidemiological perspective. Edinburgh, Churchill Livingstone, $1983: 122-64$.

[4]. Zimmet P. Type 2 (non-insulin-dependent) diabetes - an epidemiological overview. Diabetologia, 1982, 22(6):399-411.

[5]. Zimmet P. Epidemiology of diabetes mellitus. In: Ellenberg M, Riffin H, eds. Diabetes mellitus-therapy and clinical practice, 3rd ed. New York, Medical Examination Publishing, 1983:451.

[6]. Zimmet P et al. The high prevalence of diabetes mellitus, impaired glucose tolerance and diabetic retinopathy in Nauru - the 1982 survey. Diabetes research, 1984, 1:13-8.

[7]. Ekoe JM. Recent trends in prevalence and incidence of diabetes mellitus syndrome in the world. Diabetes research and clinical practice, 1986, 1:249-64.

[8]. World Health organization Department of Noncommunicable Disease Surveillance, "Diagnosis and classification of diabetes mellitus and its complications," WHO, 1999,. http://whqlibdoc.who.int/hq/1999/WHO NCD NCS 99.2.pdf.

[9]. Prof. Mansour M. Al-Nozha et al., "Diabetes Mellitus in Saudi Arabia”, Saudi Medical Journal 2004, Vol 25(11), p.1063.

[10]. S. Wild, G. Roglic, A. Green, R. Sicree, and H. King, "Global prevalence of diabetes: estimates for the year 2000 and projections for 2030," Diabetes Care, vol. 27, no. 5, pp. 1047-1053, 2004.

[11]. Al-Nozha MM, Al-Maatouq MA, Al-Mazrou YY, Al-Harthi SS. A Diabetes mellitus in Saudi Arabia. Saudi Med J. 2004; 25: 1603-10.

[12]. Elhadd TA, Al-Amoudi AA, Alzahrani AS. Epidemiology, clinical and complications profile of diabetes in Saudi Arabia: A review. Ann Saudi Med. 2007;4:241-50.

[13]. L. Alhyas, A. McKay, A. Balasanthiran, and A. Majeed, "Prevalences of overweight, obesity, hyperglycaemia, hypertension and dyslipidaemia in the Gulf: systematic review," Journal of the Royal Society of Medicine, vol. 2, p. 55, 2011.

[14]. Al-Nozha Mansour M., et al., Diabetes mellitus in Saudi Arabia, Saudi Medical Journal: 25 (11); 1603-1610.

[15]. International Diabetes Federation: Fifth Edition Diabetes Atlas 2012

[16]. Al-Almaie SM. Prevalence of obesity and overweight among Saudi adolescents in Eastern Saudi Arabia. Saudi Med J. $2005 ; 26: 607-11$.

[17]. Over weight and Obesity. http://www.who.int/mediacentre/factsheets/fs311/en/ Accessed on 18th, January, 2012

[18]. Hassan H Fatani, MRCP(UK), Siraj A Mira, MRCP(UK) and Ahmed G El-Zubier, MRCPI Prevalence of Diabetes Mellitus in Rural Saudi Arabia, DIABETES CARE, VOL. 10 NO. 2, MARCH-APRIL 1987

[19]. Sarah Wild, MB BCHIR, PHD, Gojka Roglic, MD, Anders Green, D, PHD, DR MED SCI, Richard Sicree, MBBS, MPH and Hilary King, MD, DSC Global Prevalence of Diabetes Estimates for the year 2000 and projections for 2030, American Diabetes Association, Diabetes Care 27:1047-1053, 2004.

[20]. J.E. Shaw, R.A. Sicree, P.Z. Zimmet, Global estimates of the prevalence of diabetes for 2010 and 2030,Elsevier, Diabetes Research and Clinical Practice 87 ( 2010$) 4-14$.

[21]. Khalid A. Alqurashi, Khalid S. Aljabri, and Samia A. Bokhari, Prevalence of diabetes mellitus in a Saudi community Annals of Saudi Medicine v.31(1); Jan-Feb 2011PMC3101719

[22]. El-Hazmi MAF, Warsy AS. Prevalence of obesity in the Saudi population. Annals of Saudi medicine, 1997, 17(3):302-6.

[23]. Mohsen A.F. El-Hazmi, A.S. Warsy, A.R. Al-Swailem, A.M. Al-Swailem and R. Sulaimani, Diabetes mellitus as a health problem in Saudi Arabia, Saudi Stroke Association. 